\title{
Mitochondrial Function and Insulin Resistance during Aging - A Mini-Review
}

\author{
Esther Phielix ${ }^{\mathrm{a}} \quad$ Julia Szendroedi ${ }^{\mathrm{a}-\mathrm{c}}$ Michael Roden ${ }^{\mathrm{a}-\mathrm{c}}$ \\ anstitute for Clinical Diabetology, German Diabetes Center, and ${ }^{b}$ Department of Metabolic Diseases, \\ University Clinics Düsseldorf, Heinrich-Heine University, Düsseldorf, Germany; ${ }^{\complement}$ Karl-Landsteiner Institute for \\ Endocrinology and Metabolism, Vienna, Austria
}

\section{Key Words}

Mitochondrial function - ATP synthesis • Insulin resistance • Type 2 diabetes

\begin{abstract}
Background: Insulin resistance, i.e. impaired insulin sensitivity, and type 2 diabetes are more prevalent in elderly humans. Both conditions relate to lower aerobic performance and increased body fatness, which have been linked to reduced mitochondrial oxidative capacity. Thus, lower insulin sensitivity in the elderly could result from age-related diminished energy metabolism or from lifestyle-related abnormalities. Objective: This review addresses the question whether insulin sensitivity and mitochondrial oxidative capacity are independently affected during aging and type 2 diabetes. Methods: Only studies were analyzed which included elderly persons and employed state-of-the-art methodology to assess insulin sensitivity and oxidative capacity, e.g. electron microscopic imaging, in vivo magnetic resonance spectroscopy or ex vivo high-resolution respirometry. Results: Humans with or at risk of type 2 diabetes frequently exhibit insulin resistance along with structural and functional abnormalities of muscular mitochondria. Low mitochondrial oxidative capacity causes muscular fat accumulation, which impedes insulin signaling via lipid intermediates,
\end{abstract}

in turn affecting oxidative capacity. However, insulin sensitivity is not generally reduced with age, when groups are carefully matched for physical activity and body fatness. Moreover, lifestyle intervention studies revealed discordant responses of mitochondrial oxidative capacity and insulin sensitivity. Conclusions: In the elderly, low mitochondrial oxidative capacity likely results from age-related effects acquired during life span. Insulin resistance occurs independently of age mostly due to unhealthy lifestyle on top of genetic predisposition. Thus, insulin sensitivity and mitochondrial function may not be causally related, but mutually amplify each other during aging.

Copyright $\odot 2010$ S. Karger AG, Basel

\section{Theories of Aging}

Substantial variability exists in the individual rates of aging, as the chronological age does not perfectly match with the functional age. This seems to be largely determined by genetic predisposition, but likely influenced by environmental factors. Even in less-complex organisms such as yeast and Caenorhabditis elegans, the underlying mechanisms of aging remain to be elucidated, let alone the biological basis of aging in humans. Several molecular aging theories and hypotheses have been generated.

\section{KARGER}

Fax +4161306 1234 E-Mail karger@karger.ch www.karger.com
(C) 2010 S. Karger AG, Basel

0304-324X/11/0575-0387\$38.00/0

Accessible online at:

www.karger.com/ger
Univ. Prof. Dr. med. Michael Roden, Institute for Clinical Diabetology

German Diabetes Center, Department of Metabolic Diseases, University Clinics

Heinrich-Heine University, Auf'm Hennekamp 65, DE-40225 Düsseldorf (Germany)

Tel. +49 2113382 201, Fax +492113382691

E-Mail michael.roden@ddz.uni-duesseldorf.de 
The reproductive-cell cycle theory postulated that reproductive hormones in later life regulate aging by changing the life cycle of cells. According to the aging-clock theory, chromosomal end structures, the telomeres, shorten with every cell division, which may finally prevent further cell multiplication [1]. Moreover, without these telomeres, genetic material would be lost upon every cell division. Structure and maintenance of the telomeres are of great importance, as mutations in the telomerase gene will cause aplasticanemia, pulmonary and hepatic fibrosis, cancer and cardiovascular disease. The free radical theory of aging, as first proposed in 1954 [2], aims to explain a great part of the changes in physical capacity observed during aging and age-related diseases, such as type 2 diabetes mellitus (T2DM). It postulates that the common aging process is the initiation of free radical reactions. Highly reactive intermediates, reactive oxygen species (ROS), such as superoxide $\left(\mathrm{O}_{2}\right)$ and hydroxyl $\left(\mathrm{HO}^{*}\right)$ should be responsible for the progressive degradation of biological systems thereby decreasing life span. In 1972, the free radical theory of aging was extended by suggesting that mitochondria are the origin of ROS as inevitable byproducts of oxidative phosphorylation [3]. Mitochondrial structures, such as mitochondrial DNA (mtDNA) and enzymes, are located close to the sites of ROS production and are less protected against oxidative damage due to the lack of histone protection and repair enzymes as seen for nuclear DNA. This mitochondrial theory of aging postulates that mtDNA damage accumulates during life span and eventually leads to loss of specific cell function, i.e. reduced functionality of enzyme complexes of the electron transport chain (ETC), ATP production and cell death. Thus, both the mitochondrial and the free radical theories of aging are closely linked to each other as mtDNA damage underlies both concepts.

\section{Definitions of Mitochondrial Function}

In recent years, the role of mitochondria has gained much interest in the fields of endocrinology and metabolism as mitochondrial abnormalities were found in insulin resistance and T2DM. Oxidative capacity depends on adequate mitochondrial content and/or individual mitochondrial functionality, also termed as normal mitochondrial fitness [4]. The question at what level impaired mitochondrial oxidative capacity occurs is still under debate. As previously reviewed $[4,5]$, mitochondrial abnormalities comprise decreased activity of marker enzymes of oxidative pathways in myocytes from insulin resistant obese humans and patients with T2DM. Reduction of $\mathrm{NADH}: \mathrm{O}_{2}$ oxidoreductase and NADH-dehydrogenase subunit (ND), as markers for overall ETC activity, as well as citrate synthase (CS), points towards impaired mitochondrial content [6]. Likewise, electron-microscopic imaging revealed smaller mitochondria in both obese and T2DM compared to lean humans. Interestingly, mitochondrial area also correlated positively with the degree of insulin sensitivity [6]. Furthermore, electron microscopic imaging identified different pools of myocellular mitochondria, of which the vast majority is located between the contractile filaments (intermyofibrillar mitochondria). These intermyofibrillar mitochondria are physically and possibly functionally distinct from mitochondria directly adjacent to the sarcolemma (subsarcolemmal mitochondria), which were recently shown to be reduced in T2DM [7]. Overall, the results suggest that insulin resistance and T2DM are characterized by altered mitochondrial enzyme activity and morphology. Lower oxidative capacity could be the result of lower mitochondrial content $[6,8]$ or true lower intrinsic functionality per mitochondrion $[7,9,10]$.

\section{Measurements of Mitochondrial Content and Function}

The question whether lower mitochondrial fitness or oxidative capacity in aging and T2DM are accounted for by a diminished mitochondrial content or functionality is still unclear.

Several markers for mitochondrial content are currently in use, such as mtDNA copy number, CS activity or protein subunits of the ETC complexes. Mitochondrial biogenesis is under the control of PPAR coactivators $\alpha$ $(\mathrm{PGC} 1 \alpha)$ and $\beta$ (PGC1 $\beta$ ), an inducible transcriptional coactivator which stimulates transcription of many mitochondrial genes via nuclear respiratory factor 1 (NRF1) and upregulates mitochondrial transcription factor $\mathrm{A}$ (TFAM), an important regulator of mtDNA replication and transcription. Enzymatic markers for mitochondrial content, like CS activity, are known to increase upon exercise intervention, mostly due to mitochondrial biogenesis, but may also result from increased activity per mitochondrion. This suggests that enzyme activities alone cannot suffice to interpret mitochondrial content so that other markers for mitochondrial content, like mtDNA copy number, ETC protein subunits or expression of PGC1 $\alpha$ and its downstream effector, cytochrome oxidase 1 (COX1), have to be taken into account. As physical activ- 
ity is an important determinant of mitochondrial biogenesis in the elderly [11] and in insulin resistant states such as T2DM $[12,13]$, studies examining mitochondrial function should aim at exact matching of groups for habitual physical activity. Differences in habitual physical activity and use of different markers for mitochondrial content may explain contradictory results between studies, with some [14], but not all [7, 10] studies showing altered mitochondrial content between T2DM and control groups.

As for mitochondrial content, several methods are employed to assess mitochondrial function. Biochemical measurement of oxidative enzyme activities, such as succinate dehydrogenase $(\mathrm{SDH})$ and $\mathrm{ND}$, are commonly used as these enzymes reflect ETC capacity. Furthermore, mitochondrial oxygen $\left(\mathrm{O}_{2}\right)$ consumption can be examined ex vivo in intact isolated mitochondria or in permeabilized muscle fibers using high-resolution respirometry. This method allows measuring substrate oxidation coupled to energy production by addition of various substrates or inhibitors of the ETC complexes [15]. Moreover, maximal oxidative ETC capacity can be determined by addition of carbonylcyanide- $p$-trifluoromethoxyphenylhydrazone (FCCP), a chemical uncoupler enabling proton dissipation through the inner mitochondrial membrane, thereby inducing a proton gradient loss which is compensated for by maximal $\mathrm{O}_{2}$ consumption. Nowadays, phosphorus magnetic resonance spectroscopy $\left({ }^{31} \mathrm{P}\right.$ MRS) represents the state-of-the art methodology to assess in vivo mitochondrial function non-invasively and in real time mode. As previously reviewed, two different ${ }^{31} \mathrm{P}-\mathrm{MRS}$ techniques are currently applied, the ATP saturation transfer experiment and the measurement of postexercise creatine phosphate (PCr) recovery $[4,16]$. The ATP saturation transfer experiment yields the rate of unidirectional flux through ATP synthase (ATP synthetic flux, fATP or fATPase) at rest. Using a specific radiowave pulse sequence, the ATP signal is temporarily suppressed and the subsequent changes of the steady state signal derived from myocellular inorganic phosphate $\left(\mathrm{P}_{\mathrm{i}}\right)$ are monitored to calculate fATPase from the exchange constant, $k$ value of the reaction $\mathrm{P}_{\mathrm{i}}+\mathrm{ADP}$ yielding ATP. High fATPase values indicate good mitochondrial oxidative capacity, whereas low values reflect reduced mitochondrial oxidative capacity as observed in mitochondrial diabetes [17]. The PCr recovery assesses mitochondrial oxidative capacity under conditions of increased metabolic demand. The kinetics of myocellular PCr are determined during recovery from submaximal exercise, which requires oxidative ATP generation. The full recovery after exercise can be fit into a mono-exponential time course which yields the half-time time constant of recovery, PCr- $\mathrm{t}_{1 / 2}$. Fast PCr- $\mathrm{t}_{1 / 2}$ reflects good mitochondrial oxidative capacity, whereas prolonged recovery indicates reduced mitochondrial oxidative capacity as observed in the mitochondrial disorder, Friedreich ataxia [18]. These in vivo measurements are of great relevance not only because of their non-invasiveness but also due to the possibility of repeated measurements in an identical, representative volume of one skeletal muscle. Of note, the in vivo measures of mitochondrial oxidative capacity, fATPase or PCr- $t_{1 / 2}$, can be influenced by several factors, such as blood perfusion, circulating hormones and metabolites, and do not allow to discriminate between changes in mitochondrial content or lower function per mitochondrion. Thus, the best approach for assessing mitochondria in humans is the combination of biochemical with functional measurements, e.g. $\mathrm{O}_{2}$ consumption normalized to mitochondrial content by high-resolution respirometry, with examination of in vivo determination of mitochondrial oxidative capacity using ${ }^{31} \mathrm{P}-\mathrm{MRS}$.

\section{Impaired Mitochondrial Fitness in Metabolic Diseases}

Lower mitochondrial oxidative capacity has been linked to numerous conditions with striking metabolic aberrations such as skeletal muscle insulin resistance [19]. In addition, PGC1 $\alpha$, which controls major oxidative genes involved in mitochondrial respiration and biogenesis, may induce a fiber-type switch from a glycolytic to a more oxidative muscular phenotype [20]. Several studies confirmed compromised mitochondrial fitness in skeletal muscle in T2DM, primarily due to lower mitochondrial content and possibly also due to reduced intrinsic mitochondrial functionality. As shown in figure 1, in vivo MRS studies point towards lower mitochondrial oxidative capacity in humans with T2DM compared to carefully matched controls $[10,21,22]$ as well as in firstdegree relatives (FDR) of patients with T2DM [23] and in the elderly [19]. However, other studies did not find lower in vivo mitochondrial function in T2DM $[24,25]$. Interestingly, insulin sensitivity, expressed as insulin-stimulated whole body glucose disposal, correlated positively with in vivo fATPase (fig. 2) and fasting plasma glucose concentrations correlated positively with $\mathrm{PCr}-\mathrm{t}_{1 / 2}[21]$ indicating lower mitochondrial oxidative capacity with progression of the disease. Recently, combined measurement of in vivo and ex vivo mitochondrial function in T2DM, FDR and control subjects, all carefully matched 
Fig. 1. In vivo mitochondrial function using ${ }^{31} \mathrm{P}$-MRS. a Rates of ATP synthetic flux (fATPase; $\mu \mathrm{mol} \mathrm{g}{ }^{-1} \cdot \mathrm{min}^{-1}$ ) at baseline and during insulin stimulation in obese type 2 diabetic patients (T2DM; black bar), age and BMI-matched controls (grey bar) and young BMI-matched controls (white bar): * $\mathrm{p}<0.05$ between T2DM and younger controls; ${ }^{*} \mathrm{p}<0.05$ between insulin-stimulated and basal condition [22]. b PCr recovery half-time (s) in T2DM (black bar), first-degree relatives of T2DM (grey bar) and age and BMI-matched controls (white bar): ${ }^{*} \mathrm{p}<0.05$ type 2 diabetic patients vs. controls [10].

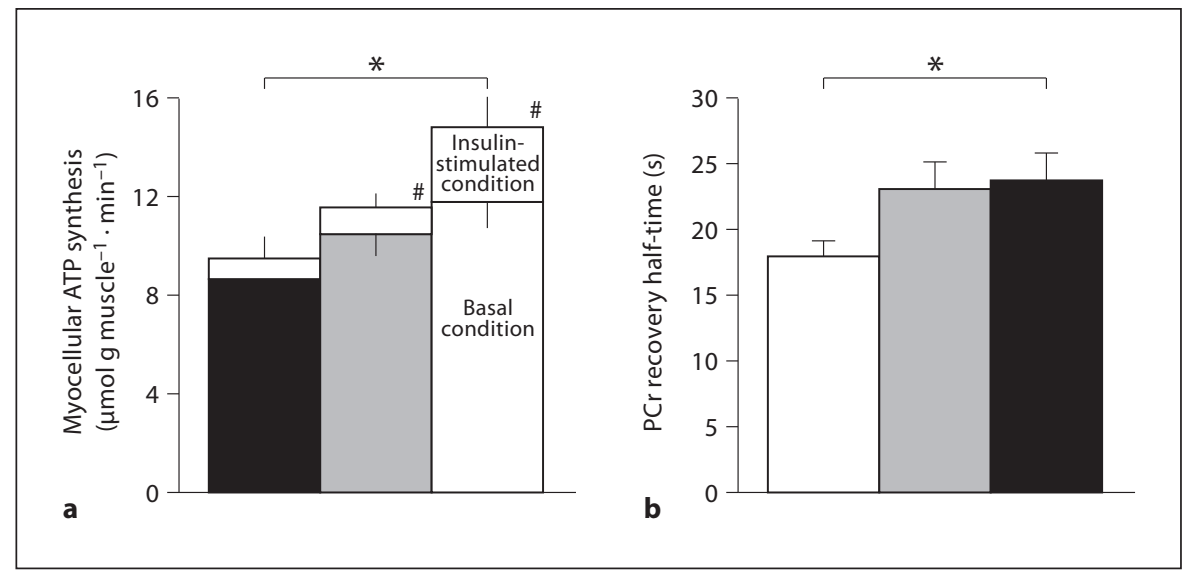

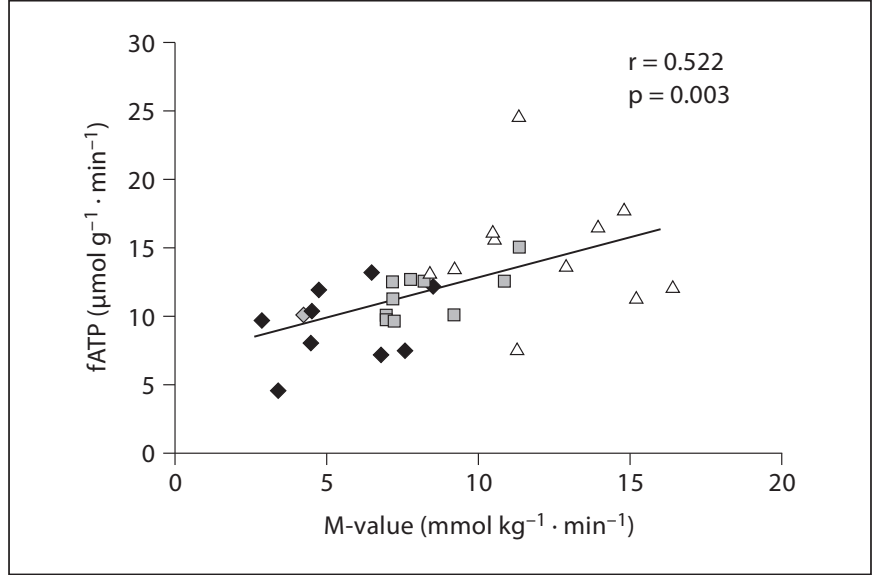

Fig. 2. Significant relationships between in vivo mitochondrial function (fATPase) and insulin sensitivity (expressed as M-value). Correlation between fATPase during insulin stimulation and $\mathrm{M}$-value in healthy young (triangles), elderly (squares) and T2DM persons (diamonds) [22].

for age and body fatness, revealed the underlying mechanisms of lower oxidative capacity [10] (fig. 1b). Both substrate-coupled oxidative phosphorylation (state 3 respiration) on glutamate, succinate and palmitoyl-carnitine and maximal oxidative mitochondrial capacity (state $u$ respiration) assessed with the chemical uncoupler FCCP were decreased (fig. 3). Markers for mitochondrial content, mtDNA copy number and CS activity, were not different between all three groups, the normalized respiratory values for mitochondrial content remained lower in T2DM and FDR indicating intrinsic compromised mitochondrial functionality. As ex vivo respiratory values

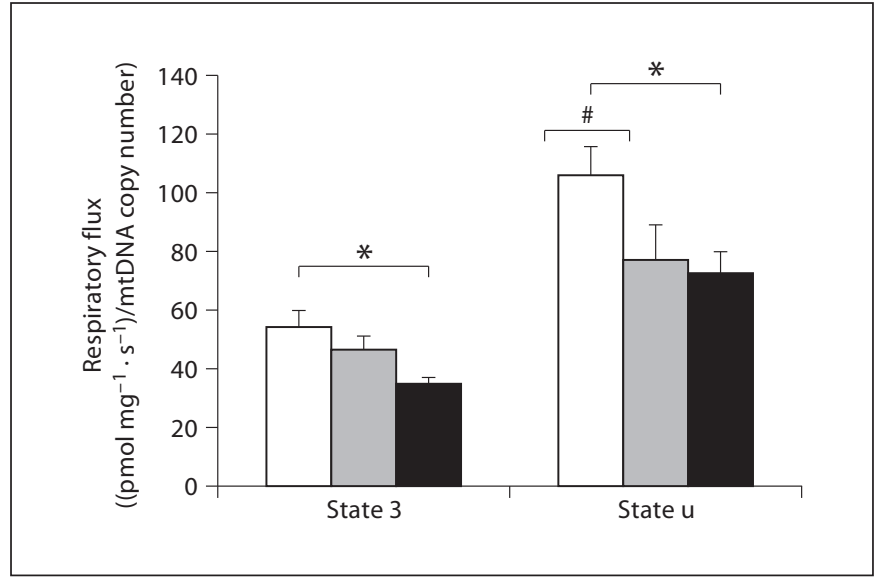

Fig. 3. Ex vivo mitochondrial function. State 3 and state $u$ respiration normalized for mitochondrial content expressed as (pmol $\left.\mathrm{s}^{-1} \cdot \mathrm{mg}^{-1}\right) / \mathrm{mtDNA}$ copy number in T2DM (black bars), first-degree relatives of T2DM (grey bars) and controls (white bars). ${ }^{*} \mathrm{p}<0.05$ compared with diabetic patients; ${ }^{*}$ n.s. $(\mathrm{p}=0.10)$ in FDR vs. controls [10].

correlated with in vivo $\mathrm{PCr}-\mathrm{t}_{1 / 2}$, lower mitochondrial functionality at the level of oxidative phosphorylation likely underlies lower in vivo mitochondrial function [10]. The finding of lower mitochondrial functionality was in line with a study of Mogensen et al. [9], who found lower state 3 respiration on the glycolytic substrate, pyruvate, in T2DM compared to age- and body mass-matched controls, regardless of mitochondrial content based on comparable CS activities in both groups. State 3 respiration further correlated negatively with glycemic control as assessed from hemoglobin A1c (HbA1c) levels, again supporting blunting of mitochondrial function with pro- 
gression of the disease. Boushel et al. [8] found lower mitochondrial oxidative capacity in T2DM, but no alteration of mitochondrial functionality upon normalization for mtDNA copy number and CS activity. Of note, these authors did not report glycemic control in these T2DM. Together, in vivo and ex vivo data strongly suggest an important role of mitochondrial function related to T2DM due to reduced intrinsic mitochondrial functionality or content.

\section{Low Mitochondrial Oxidative Capacity and Insulin Resistance}

Insulin resistance precedes and predicts T2DM, which is best documented for insulin resistant humans with a family history of T2DM, such as FDR [10, 23]. Of note, severely insulin resistant FDR also have a lower in vivo mitochondrial function and therefore compromised mitochondrial function is hypothesized to be an early defect in the pathogenesis of T2DM [23]. Recently, comparison of age- and body mass-matched FDR, T2DM and controls, revealed only gradually lower mitochondrial oxidative capacity in the risk group [10] (fig. 1b). Interestingly, these FDR were not as insulin resistant as T2DM, suggesting that lower mitochondrial oxidative capacity may be influenced by both inherited factors and acquired factors such as high caloric diet and sedentary lifestyle. In line with this contention, in vivo oxidative capacity as assessed from fATPase also relates to and is partly explained by plasma concentrations of free fatty acids (FFA), which in turn predict the development of T2DM [22]. Alternatively, lower mitochondrial oxidative capacity may underlie increased deposition of triglycerides (TG) in skeletal muscle (intramyocellular triglycerides, IMTG) or other tissues such as liver and heart, termed ectopic fat accumulation, which is known to be associated with aging, obesity and T2DM [26, 27]. Lower mitochondrial oxidative capacity combined with elevated fasting plasma FFA as seen in obesity and T2DM may therefore cause ectopic fat accumulation and insulin resistance. Operation of such mechanism was supported by the finding that fATPase decreased by $\sim 24 \%$ in healthy young men upon lipid infusion, inducing a physiological rise of both plasma FFA and TG [28]. Elevated FFA supply exceeding the myocellular fat oxidative capacity may be responsible for the accumulation of IMTG and lipid metabolites, such as diacylglycerols, fatty-acyl-CoAs and ceramides, which are accused of impeding insulin signaling and lowering glucose uptake $[29,30]$. The question arises whether low- er mitochondrial fitness in the presence of high IMTG content really causes insulin resistance and development of T2DM or vice versa, in which lower oxidative capacity results from insulin resistance and high IMTG content via a process called lipotoxicity. In addition, accumulating fatty acids within myocytes are prone to interact with ROS-forming lipid peroxides exerting lipotoxic effects on cellular structures including mitochondria [31]. Most likely, compromised mitochondrial oxidative capacity as seen in T2DM could exacerbate and further raise IMTG levels. Recent reports from intervention studies employing exercise training and weight loss in T2DM failed to confirm a straightforward relationship between changes in mitochondrial function and insulin sensitivity. Combined exercise plus weight loss intervention resulted in increased insulin sensitivity and improved mitochondrial function, but weight loss alone also increased insulin sensitivity but without concomitant improvement of mitochondrial function [32]. A recent exercise training study found completely restored in vivo and ex vivo mitochondrial function in T2DM, mainly due to enhanced mitochondrial content, while insulin sensitivity increased but did not normalize $[12,33]$. These data suggest that mitochondrial function and insulin sensitivity are not per se causally related.

\section{Low Mitochondrial Oxidative Capacity: A Consequence of Aging?}

There is evidence that insulin sensitivity declines with aging, which could explain the high prevalence of T2DM in the elderly $[19,34]$. Petersen et al. [19] were the first to demonstrate that elderly humans have elevated IMTG and intrahepatic TG content as well as reduced whole body insulin sensitivity and in vivo oxidative capacity, as shown by $\sim 40 \%$ lower flux rates through the tricarboxic acid cycle and ATP synthase compared with younger humans (table 1). Short et al. [34] reported a progressive decline in insulin sensitivity with rising age ranging from 21 to 87 years, which was paralleled by increasing body fat content and decreasing aerobic performance. In addition, ex vivo measurements revealed lower oxidative capacity, including COX and CS activities [35-38], substrate-coupled ATP synthesis [19, 35-37] and mtDNA copy number $[34,35,38]$, which confirmed results of impaired in vivo mitochondrial function in the elderly.

Despite the postulated link between age-dependent mitochondrial dysfunction and insulin resistance, recent studies reported contradictory results suggesting that bi- 
Table 1. Overview of studies comparing insulin sensitivity and/or body fatness with mitochondrial oxidative capacity between elderly (35-84 years) and younger (18-47 years) groups of humans

\begin{tabular}{|c|c|c|c|c|c|c|c|}
\hline Study & $\begin{array}{l}\text { IS } \\
\text { assess- } \\
\text { ment }\end{array}$ & $\begin{array}{l}\text { IR state of } \\
\text { elderly compa- } \\
\text { red to young } \\
\text { controls }\end{array}$ & Age, years & $\begin{array}{l}\text { Matched for } \\
\text { physical activity }\end{array}$ & $\begin{array}{l}\text { Matched for } \\
\text { body mass fat } \\
\text { content }\end{array}$ & $\begin{array}{l}\text { Mitochondrial } \\
\text { function assessment }\end{array}$ & $\begin{array}{l}\text { Mitochondrial dysfunction in } \\
\text { elderly }\end{array}$ \\
\hline $\begin{array}{l}\text { Amati et al., } \\
2009 \text { [39] }\end{array}$ & $\begin{array}{l}\text { insulin- } \\
\text { stimula- } \\
\text { ted Rd }\end{array}$ & elderly & $\begin{array}{l}\text { elderly } 60-75 \\
\text { young } 27-47\end{array}$ & $\begin{array}{l}\text { yes }\left(\sim \mathrm{VO}_{2} \max \right. \\
\text { between elderly } \\
\text { and young })\end{array}$ & $\begin{array}{l}\text { no (elderly } \uparrow \% \\
\text { body fat) }\end{array}$ & no & \\
\hline $\begin{array}{l}\text { Petersen et al., } \\
2003 \text { [19] }\end{array}$ & $\begin{array}{l}\text { GIR } \\
\text { during } \\
\text { clamp }\end{array}$ & $\begin{array}{l}\text { elderly } \\
\downarrow \text { GIR }\end{array}$ & $\begin{array}{l}\text { elderly } 61-84 \\
\text { young } 18-39\end{array}$ & $\begin{array}{l}\text { yes (AI, but } \\
\mathrm{VO}_{2} \text { max n.p.) }\end{array}$ & $\begin{array}{l}\text { yes }(\sim \text { body fat } \\
\% \text { in elderly and } \\
\text { young })\end{array}$ & $\begin{array}{l}\text { yes (mitochondrial } \\
\text { TCA-flux and ATP- } \\
\text { synthetic rate) }\end{array}$ & $\begin{array}{l}\text { yes } \\
-40 \% \downarrow \text { TCA flux } \\
-40 \% \downarrow \text { ATP synthetic rate }\end{array}$ \\
\hline $\begin{array}{l}\text { Szendroedi } \\
\text { et al., } \\
2007[22]\end{array}$ & $\begin{array}{l}\text { GIR } \\
\text { during } \\
\text { clamp }\end{array}$ & $\begin{array}{l}\text { elderly } \\
\downarrow \text { GIR }\end{array}$ & $\begin{array}{l}\text { elderly } 46-65 \\
\text { young } 21-28\end{array}$ & $\begin{array}{l}\text { yes (AI, but } \\
\mathrm{VO}_{2} \text { max n.p.) }\end{array}$ & $\begin{array}{l}\text { no (body fat } \\
\text { content n.p., } \\
\text { although no } \\
\text { differences in } \\
\text { WHR) }\end{array}$ & $\begin{array}{l}\text { yes (in vivo ATP } \\
\text { synthetic rate) }\end{array}$ & $\begin{array}{l}\text { no } \\
-\sim \text { ATP synthetic rate }\end{array}$ \\
\hline $\begin{array}{l}\text { Crane et al., } \\
2009[38]\end{array}$ & $\begin{array}{l}\text { HOMA-R } \\
\text { index }\end{array}$ & elderly & $\begin{array}{l}\text { elderly } 71 \pm 2 \\
\text { young } 23 \pm 2\end{array}$ & $\begin{array}{l}\text { yes (aerobic } \\
\text { exercise: } \min / \text { week, } \\
\text { but no } \mathrm{VO}_{2} \max \\
\text { n.p.) }\end{array}$ & $\begin{array}{l}\text { no (elderly } \uparrow \% \\
\text { body fat) }\end{array}$ & $\begin{array}{l}\text { yes } \\
\text { (COX and CS } \\
\text { activity, } \\
\text { mitochondrial } \\
\text { morphology) }\end{array}$ & $\begin{array}{l}\text { yes } \\
-43 \% \downarrow \text { COX activity } \\
-33 \% \downarrow \text { CS activity } \\
-\quad \downarrow \text { mitochondrial content } \\
\quad\left(\mathrm{n} / \mu \mathrm{m}^{2}\right) \\
-\quad \downarrow \text { mitochondrial density }(\%)\end{array}$ \\
\hline $\begin{array}{l}\text { Lanza et al., } \\
2008[35]\end{array}$ & $\begin{array}{l}\text { insulin- } \\
\text { stimula- } \\
\text { ted Rd }\end{array}$ & elderly & $\begin{array}{l}\text { elderly } 59-76 \\
\text { young } 18-30\end{array}$ & $\begin{array}{l}\text { yes (leisure-time } \\
\text { activity } \\
\text { questionnaire, but } \\
\downarrow \mathrm{VO}_{2} \mathrm{max} \text { in } \\
\text { elderly) }\end{array}$ & $\begin{array}{l}\text { yes }(\sim \text { body fat } \\
\% \text { in elderly and } \\
\text { young })\end{array}$ & $\begin{array}{l}\text { yes (mitochondrial } \\
\text { ATP production } \\
\text { capacity, CS activity } \\
\text { and mtDNA copy } \\
\text { number) }\end{array}$ & $\begin{array}{l}\text { yes } \\
\text { - } \downarrow \text { MAPR on glutamate, } \\
\quad \text { succinate and palmitoyl- } \\
\quad \text { carnitine } \\
\text { - } \downarrow \text { CS activity } \\
\text { - } \downarrow \text { mtDNA copy number }\end{array}$ \\
\hline $\begin{array}{l}\text { Short et al., } \\
2005 \text { [37] }\end{array}$ & $\begin{array}{l}\text { not } \\
\text { deter- } \\
\text { mined }\end{array}$ & $\begin{array}{l}\text { n.p. } \\
\text { although } \\
\text { elderly were } \\
\text { lower glu- } \\
\text { cose tolerant }\end{array}$ & $\begin{array}{l}\text { elderly } 35-57 \\
\text { young } 18-33\end{array}$ & $\begin{array}{l}\text { yes ( similar } \\
\text { physical activity } \\
\text { level, but } \downarrow \mathrm{VO}_{2} \text { max } \\
\text { in elderly) }\end{array}$ & $\begin{array}{l}\text { no }(\uparrow \% \text { body fat } \\
\text { in elderly) }\end{array}$ & $\begin{array}{l}\text { yes (mitochondrial } \\
\text { ATP production } \\
\text { capacity, CS } \\
\text { activity) }\end{array}$ & $\begin{array}{l}\text { yes } \\
-\downarrow \text { MAPR on glutamate, } \\
\text { succinate and palmitoyl- } \\
\text { carnitine } \\
\text { - } \downarrow \text { CS activity }\end{array}$ \\
\hline $\begin{array}{l}\text { Tonkonogi } \\
\text { et al., } \\
2003[36]\end{array}$ & $\begin{array}{l}\text { not } \\
\text { deter- } \\
\text { mined }\end{array}$ & n.p. & $\begin{array}{l}\text { elderly } 63-80 \\
\text { young } 22-31\end{array}$ & $\begin{array}{l}\text { yes ( } \text { similar } \\
\text { physical activity } \\
\text { level, but } \downarrow \mathrm{VO}_{2} \text { max } \\
\text { in elderly) }\end{array}$ & $\begin{array}{l}\text { no (body fat } \\
\text { content n.p.) }\end{array}$ & $\begin{array}{l}\text { yes (CS an COX } \\
\text { activity) }\end{array}$ & $\begin{array}{l}\text { yes } \\
-\quad \downarrow \text { COX activity } \\
-\quad \downarrow \text { ADP-stimulated } \\
\quad \text { respiratory rates }\end{array}$ \\
\hline
\end{tabular}

Insulin sensitivity (IS) was assessed either from clamp tests and expressed as insulin-stimulated glucose disposal (Rd) or glucose infusion rate (GIR or M-value) or from fasting glucose and insulin concentrations and expressed as the HOMA-R index. Physical activity was assessed either from aerobic cycling spiroergometry and given as maximal oxygen uptake $\left(\mathrm{VO}_{2} \mathrm{max}\right)$ or from questionnaires and given mostly as activity index (AI). Body fatness was given as body fat percentage (\%fat) or waist-to-hip ratio (WHR).
TCA = Tricarboxylic acid cycle; $\mathrm{CS}=$ citrate synthase; $\mathrm{COX}=$ cytochrome oxidase; $\mathrm{mtDNA}=$ mitochondrial DNA copy number; $\mathrm{MAPR}=$ mitochondrial ATP production rate; arrows indicate higher or lower, ' ' similar levels compared to the respective control group; n.p. = not presented. ological aging per se may not relate to insulin resistance, but rather results from reduced physical activity and increased fat deposition (table 1). Particularly, when groups of different age were carefully matched for the degree of physical activity, similar values for insulin sensitivity were seen between groups [35, 38, 39]. However, regardless of insulin sensitivity, the studies listed in table 1 showed reduced ex vivo oxidative capacity at the levels of lower enzyme activities, substrate-coupled ATP synthesis and/or mitochondrial content in skeletal muscle of the elderly. Likewise, the elderly groups featured lower in vivo oxidative capacity as determined from aerobic performance, despite matching for physical activity levels $[19,35-38,40]$. Overall, body fat content was higher in the 
elderly except for three studies with matched body fat content between the groups $[19,35,40]$. Of note, Szendroedi et al. [22] showed similar baseline in vivo mitochondrial function despite lower insulin sensitivity in their elderly compared with the younger participants, who were matched for physical activity and body mass. Of note, this does not exclude subtle differences in $\mathrm{VO}_{2}$ max or body fat percentage. Taken together, low mitochondrial oxidative capacity seemed to be a direct effect of chronological age, in contrast to insulin resistance, as no age effect was found for insulin sensitivity when matched for body fat content. These results furthermore suggest that compromised mitochondrial function and insulin resistance are not per se causally related in aging (fig. 4).

\section{Is Aging Reversible?}

As insulin sensitivity and mitochondrial oxidative capacity both decline with aging, the questions arise whether these abnormalities are inevitable consequences of age and whether they are reversible or can be prevented. To this end, several studies examined the effects of short-term exercise training intervention in the elderly and convincingly showed improvements in mitochondrial enzyme activities (ND, SDH, CS and COX), expression of mitochondrial genes (COX4 and ND subunit 4 (ND4)) and transcription factors controlling mitochondrial biogenesis (PGC-1 $\alpha$, TFAM and NRF1) as well as indicators of mitochondrial content (mtDNA copy number and cardiolipin) $[34,41-43]$. These improvements in mitochondrial function occurred in parallel with increased aerobic performance and insulin sensitivity as assessed from HOMA-R or insulin sensitivity index (ISI). Although the lower physical activity typically observed in the elderly could result from compromised mitochondrial capacity, the exercise-induced increase in mitochondrial oxidative capacity argues against such a mechanism. Rather, lower oxidative capacity of elderly persons could result from reduced physical activity per se or other acquired alterations, e.g. protein catabolism. Of note, short-term exercise training improved but did not normalize mitochondrial function in the elderly when compared with control subjects enrolled in the identical exercise intervention [34]. Recently, studies compared chronically endurance-trained elderly and sedentary elderly persons with younger trained and younger sedentary controls to examine whether prolonged exercise training prevents the age-associated de-

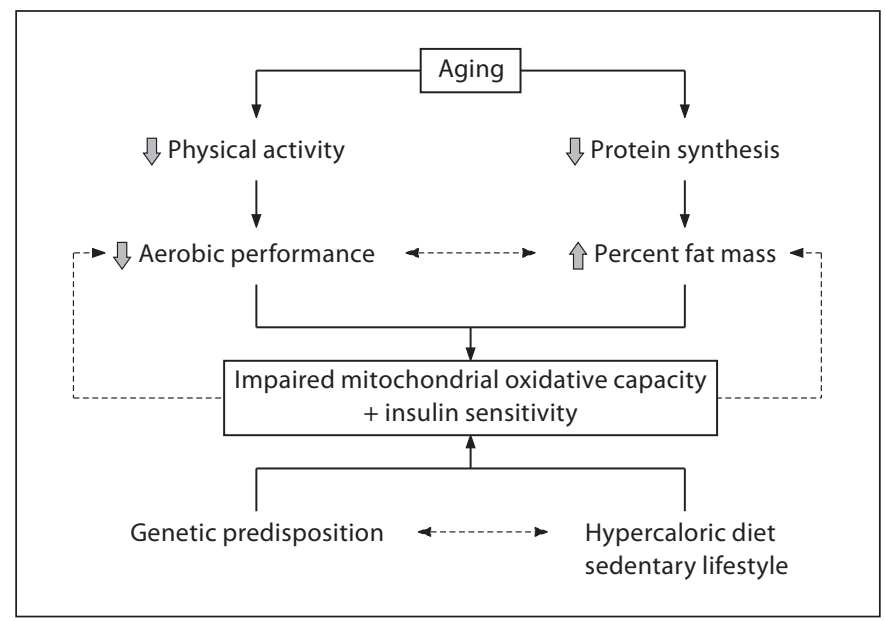

Fig. 4. Links between aging, mitochondrial function and insulin resistance. Black lines represent established relationships; broken lines represent less-supported or hypothetical interactions.

cline in insulin sensitivity and/or mitochondrial function $[35,39]$. Interestingly, insulin sensitivity in both studies, expressed as the change in insulin-stimulated glucose disposed $\left(R_{d}\right)$, was similar between the elderly endurance trained and younger trained groups, as well as between the elderly sedentary and younger sedentary controls. In addition, ex vivo mitochondrial function was also comparable, although mtDNA abundance (ND1 and ND4) and expression of PGC-1 $\alpha$ was lower in the elderly. Thus, these results suggest that insulin resistance in the elderly is rather due to physical inactivity than to aging per se. Gene-environment interactions may also contribute to the individual response to exercise training and ultimately to the degree of physical activity. A recent study demonstrated that a single nucleotide gene polymorphism (SNP) in the ND1 $\beta$ subcomplex 6 (NDUFB6) gene of ETC complex 1 defines a normal or blunted response of fATPase to short-term exercise training in glucose tolerant FDR [44]. Likewise, SNPs of PPAR $\delta$ and PGC1 $\alpha$ also influence the change of aerobic physical fitness and insulin sensitivity in vivo as well as mitochondrial function ex vivo during lifestyle intervention [45]. This is in line with an inherited abnormality of adaptive mechanisms. Muscular expression of both PGC1 $\alpha$ and PPAR $\delta$ occurs immediately or shortly after acute exercise. The latter study also reported an exerciseinduced increase in muscular mRNA expression of sirtuin-1 (SIRT1). There is growing evidence that SIRT1, a protein deacetylase allosterically activated by $\mathrm{NAD}^{+}$, is 
involved in various processes comprising cellular stress resistance, genomic stability, tumorigenesis and energy metabolism [46] and may even deacetylate and activate PGC1 $\alpha$ in rodent skeletal muscle [47]. Nevertheless, the role of SIRT1 in the human aging process and in extending the life span remains unclear.

\section{Age-Related Lower Mitochondrial Function as a Protective Mechanism?}

Lower mitochondrial function and content in the elderly could also be the result of a normal and 'healthy' aging process. It has been hypothesized that reduction of in vivo mitochondrial function, assessed from fATPase or PCr- $\mathrm{t}_{1 / 2}$ and also ex vivo lower substrate-coupled ATP production (state 3 respiration) are due to increased mitochondrial uncoupling [48]. During mitochondrial respiration, substrate oxidation and the concomitant proton transfer along the ETC generate an electrochemical proton gradient across the inner mitochondrial membrane. This proton gradient drives the backflow of protons via ATP synthase, thereby resulting in ATP production, in which fuel oxidation is coupled to energy production. $\mathrm{Mi}$ tochondrial uncoupling refers to the re-entry of protons within the matrix bypassing the ATP synthase, in which the proton gradient dissipates by proton leakage. Mitochondrial uncoupling may lower ROS production by reducing the reverse electron flow [49]. According to this concept, aging-related lowering of mitochondrial respiration resulting from mitochondrial uncoupling would serve to protect against damaging effects of ROS. So far, in vivo MRS revealed conflicting results on the postulated increased mitochondrial uncoupling in the elderly. Amara et al. [48] suggested mild uncoupling in specific type 1 muscle as protective mechanism in aging cells. Mice selectively overexpressing UCP3 in skeletal muscle also exhibited blunted age-induced increases in mitochondrial ROS production [50]. In contrast, Petersen et al. [19] found no differences in mitochondrial coupling as determined from comparable ratios of the rates of TCA flux/ATP synthetic flux between elderly and young humans. Similarly, mitochondrial uncoupling was not different between older and younger subjects, as measured ex vivo in isolated mitochondria from the $\mathrm{m}$. quadriceps femoris [36].

Finally, a certain degree of ROS production may even facilitate insulin signaling and improve metabolic pathways [51]. A recent study reported that antioxidant supplementation effectively blocked exercise-induced ROS production but in parallel prevented health-promoting effects of exercise in humans [52]. Thus, initial disruption of homeostasis, termed hormesis, may induce adaptive responses and determine the balance of life-sustaining factors aiming at prevention of aging. To which extent mitochondrial uncoupling and ROS production are involved in the age-related decline of mitochondrial oxidative capacity in humans needs future research.

\section{Conclusion}

Aging is associated with declining physical activity and anabolic reactions, i.e. impaired protein synthesis (fig. 4). With time, this will cause lower aerobic performance and augment body fat mass, both of which could reduce insulin sensitivity and mitochondrial oxidative capacity. On the other hand, genetic predisposition and 'unhealthy' lifestyle alone or by mutual interaction cause insulin resistance and lower mitochondrial oxidative capacity. Both abnormalities may further negatively affect aerobic performance and fat accumulation. While insulin resistance in individuals at high risk of T2DM is likely linked to inherited factors resulting in reduced energy metabolism, lifestyle and body fat content define the progression to T2DM. Variable responses to lifestyle intervention suggest that insulin sensitivity and oxidative capacity are not causally related in general. In the elderly, insulin resistance likely results from declining physical activity and or growing body fat content, because similar insulin sensitivity between elderly and younger groups is seen upon matching for these variables. In contrast, lower mitochondrial oxidative capacity remains a consistent feature of the elderly, confirming the acquisition of mitochondrial aberrations during life span.

\section{Acknowledgements}

The studies by the authors were supported in part by grants from the European Foundation for the Study of Diabetes (EFSD), Juvenile Diabetes Foundation (JDRF), Schmutzler-Stiftung, Skröder-Stiftung, German Research Foundation (DFG; SFB 512) and from the German Federal Ministry of Education and Research (BMBF) to the German Diabetes Center (DZD e.V.). 


\section{References}

$\checkmark 1$ Ahmed A, Tollefsbol T: Telomeres and telomerase: basic science implications for aging. J Am Geriatr Soc 2001;49:1105-1109.

$\checkmark 2$ Harman D: Aging: a theory based on free radical and radiation chemistry. J Gerontol 1956;11:298-300.

$\checkmark 3$ Harman D: Free radical theory of aging: dietary implications. Am J Clin Nutr 1972;25: 839-843.

4 Szendroedi J, Roden M: Mitochondrial fitness and insulin sensitivity in humans. Diabetologia 2008;51:2155-2167.

$\checkmark 5$ Phielix E, Mensink M: Type 2 diabetes mellitus and skeletal muscle metabolic function. Physiol Behav 2008;94:252-258.

-6 Kelley DE, He J, Menshikova EV, Ritov VB: Dysfunction of mitochondria in human skeletal muscle in type 2 diabetes. Diabetes 2002;51:2944-2950.

$\checkmark 7$ Ritov VB, Menshikova EV, He J, Ferrell RE, Goodpaster BH, Kelley DE: Deficiency of subsarcolemmal mitochondria in obesity and type 2 diabetes. Diabetes 2005;54:8-14.

8 Boushel R, Gnaiger E, Schjerling P, Skovbro M, Kraunsoe R, Dela F: Patients with type 2 diabetes have normal mitochondrial function in skeletal muscle. Diabetologia 2007; 50:790-796.

>9 Mogensen M, Sahlin K, Fernstrom M, Glintborg D, Vind BF, Beck-Nielsen H, Hojlund K: Mitochondrial respiration is decreased in skeletal muscle of patients with type 2 diabetes. Diabetes 2007;56:1592-1599.

-10 Phielix E, Schrauwen-Hinderling VB, Mensink M, Lenaers E, Meex R, Hoeks J, Kooi ME, Moonen-Kornips E, Sels JP, Hesselink MK, Schrauwen P: Lower intrinsic ADPstimulated mitochondrial respiration underlies in vivo mitochondrial dysfunction in muscle of male type 2 diabetic patients. Diabetes 2008;57:2943-2949.

-11 Lanza IR, Nair KS: Muscle mitochondrial changes with aging and exercise. Am J Clin Nutr 2009;89:467S-471S.

$\checkmark 12$ Phielix E: Exercise training increases mitochondrial content and ex vivo mitochondrial function in type 2 diabetic patients to similar levels as control subjects. Diabetologia 2010;53:1714-1721.

-13 Toledo FG, Menshikova EV, Ritov VB, Azuma K, Radikova Z, DeLany J, Kelley DE: Effects of physical activity and weight loss on skeletal muscle mitochondria and relationship with glucose control in type 2 diabetes. Diabetes 2007;56:2142-2147.

- 14 Befroy DE, Petersen KF, Dufour S, Mason GF, de Graaf RA, Rothman DL, Shulman GI: Impaired mitochondrial substrate oxidation in muscle of insulin-resistant offspring of type 2 diabetic patients. Diabetes 2007;56: 1376-1381.

15 Gnaiger E: Capacity of oxidative phosphorylation in human skeletal muscle: new perspectives of mitochondrial physiology. Int J Biochem Cell Biol 2009;41:1837-1845.
6 Schrauwen-Hinderling VB, Roden M, Kooi ME, Hesselink MK, Schrauwen P: Muscular mitochondrial dysfunction and type 2 diabetes mellitus. Curr Opin Clin Nutr Metab Care 2007;10:698-703.

17 Szendroedi J, Schmid AI, Meyerspeer M, Cervin C, Kacerovsky M, Smekal G, GraserLang S, Groop L, Roden M: Impaired mitochondrial function and insulin resistance of skeletal muscle in mitochondrial diabetes. Diabetes Care 2009;32:677-679.

-18 Meyer C, Carlqvist H, Vorgerd M, Schols L, Ostenson CG, Ristow M: Regular insulin secretory oscillations despite impaired ATP synthesis in Friedreich ataxia patients. Horm Metab Res 2006;38:683-687.

19 Petersen KF, Befroy D, Dufour S, Dziura J, Ariyan C, Rothman DL, DiPietro L, Cline GW, Shulman GI: Mitochondrial dysfunction in the elderly: possible role in insulin resistance. Science 2003;300:1140-1142.

20 Lin J, Wu H, Tarr PT, Zhang CY, Wu Z, Boss O, Michael LF, Puigserver P, Isotani E, Olson EN, Lowell BB, Bassel-Duby R, Spiegelman BM: Transcriptional co-activator PGC-1 alpha drives the formation of slow-twitch muscle fibres. Nature 2002;418:797-801.

-21 Schrauwen-Hinderling VB, Kooi ME, Hesselink MK, Jeneson JA, Backes WH, van Echteld CJ, van Engelshoven JM, Mensink M, Schrauwen P: Impaired in vivo mitochondrial function but similar intramyocellular lipid content in patients with type 2 diabetes mellitus and BMI-matched control subjects. Diabetologia 2007;50:113-120.

22 Szendroedi J, Schmid AI, Chmelik M, Toth C, Brehm A, Krssak M, Nowotny P, Wolzt M, Waldhausl W, Roden M: Muscle mitochondrial ATP synthesis and glucose transport/ phosphorylation in type 2 diabetes. PLoS Med 2007;4:e154.

23 Petersen KF, Dufour S, Befroy D, Garcia R, Shulman GI: Impaired mitochondrial activity in the insulin-resistant offspring of patients with type 2 diabetes. N Engl J Med 2004;350:664-671.

24 Trenell MI, Hollingsworth KG, Lim EL, Taylor R: Increased daily walking improves lipid oxidation without changes in mitochondrial function in type 2 diabetes. Diabetes Care 2008;31:1644-1649.

25 De Feyter HM, van den Broek NM, Praet SF, Nicolay K, van Loon LJ, Prompers JJ: Early or advanced stage type 2 diabetes is not accompanied by in vivo skeletal muscle mitochondrial dysfunction. Eur J Endocrinol 2008; 158:643-653.

26 Kelley DE, Goodpaster BH, Storlien L: Muscle triglyceride and insulin resistance. Annu Rev Nutr 2002;22:325-346.
27 Krssak M, Falk Petersen K, Dresner A, DiPietro L, Vogel SM, Rothman DL, Roden M, Shulman GI: Intramyocellular lipid concentrations are correlated with insulin sensitivity in humans: a $1 \mathrm{H}$ NMR spectroscopy study. Diabetologia 1999;42:113-116.

28 Brehm A, Krssak M, Schmid AI, Nowotny P, Waldhausl W, Roden M: Increased lipid availability impairs insulin-stimulated ATP synthesis in human skeletal muscle. Diabetes 2006;55:136-140.

29 Roden M, Price TB, Perseghin G, Petersen KF, Rothman DL, Cline GW, Shulman GI: Mechanism of free fatty acid-induced insulin resistance in humans. J Clin Invest 1996; 97:2859-2865.

30 Boden G, Lebed B, Schatz M, Homko C, Lemieux S: Effects of acute changes of plasma free fatty acids on intramyocellular fat content and insulin resistance in healthy subjects. Diabetes 2001;50:1612-1617.

31 Schrauwen P, Schrauwen-Hinderling V, Hoeks J, Hesselink MK: Mitochondrial dysfunction and lipotoxicity. Biochim Biophys Acta 1801;266-271.

32 Toledo FG, Menshikova EV, Azuma K, Radikova Z, Kelley CA, Ritov VB, Kelley DE: Mitochondrial capacity in skeletal muscle is not stimulated by weight loss despite increases in insulin action and decreases in intramyocellular lipid content. Diabetes 2008;57: 987-994.

33 Meex RC, Schrauwen-Hinderling VB, Moonen-Kornips E, Schaart G, Mensink M, Phielix E, van de Weijer T, Sels JP, Schrauwen $\mathrm{P}$, Hesselink MK: Restoration of muscle mitochondrial function and metabolic flexibility in type 2 diabetes by exercise training is paralleled by increased myocellular fat storage and improved insulin sensitivity. Diabetes 2008;59:572-579.

34 Short KR, Vittone JL, Bigelow ML, Proctor DN, Rizza RA, Coenen-Schimke JM, Nair KS: Impact of aerobic exercise training on age-related changes in insulin sensitivity and muscle oxidative capacity. Diabetes 2003;52:1888-1896.

-35 Lanza IR, Short DK, Short KR, Raghavakaimal S, Basu R, Joyner MJ, McConnell JP, Nair KS: Endurance exercise as a countermeasure for aging. Diabetes 2008;57:29332942.

36 Tonkonogi M, Fernstrom M, Walsh B, Ji LL, Rooyackers O, Hammarqvist F, Wernerman J, Sahlin K: Reduced oxidative power but unchanged antioxidative capacity in skeletal muscle from aged humans. Pflügers Arch 2003;446:261-269.

37 Short KR, Bigelow ML, Kahl J, Singh R, Coenen-Schimke J, Raghavakaimal S, Nair KS: Decline in skeletal muscle mitochondrial function with aging in humans. Proc Natl Acad Sci USA 2005;102:5618-5623. 
38 Crane JD, Devries MC, Safdar A, Hamadeh MJ, Tarnopolsky MA: The effect of aging on human skeletal muscle mitochondrial and intramyocellular lipid ultrastructure. J Gerontol A Biol Sci Med Sci 2009;65:119128.

-39 Amati F, Dube JJ, Coen PM, Stefanovic-Racic M, Toledo FG, Goodpaster BH: Physical inactivity and obesity underlie the insulin resistance of aging. Diabetes Care 2009;32: 1547-1549.

-40 Karakelides H, Irving BA, Short KR, O’Brien P, Nair KS: Age, obesity, and sex effects on insulin sensitivity and skeletal muscle mitochondrial function. Diabetes 2008;59:89-97.

-41 Menshikova EV, Ritov VB, Fairfull L, Ferrell RE, Kelley DE, Goodpaster BH: Effects of exercise on mitochondrial content and function in aging human skeletal muscle. J Gerontol A Biol Sci Med Sci 2006;61:534540.

42 Toledo FG, Watkins S, Kelley DE: Changes induced by physical activity and weight loss in the morphology of intermyofibrillar mitochondria in obese men and women. J Clin Endocrinol Metab 2006;91:3224-3227.
43 Menshikova EV, Ritov VB, Toledo FG, Ferrell RE, Goodpaster BH, Kelley DE: Effects of weight loss and physical activity on skeletal muscle mitochondrial function in obesity. Am J Physiol Endocrinol Metab 2005; 288:E818-E825.

44 Kacerovsky-Bielesz G, Chmelik M, Ling C, Pokan R, Szendroedi J, Farukuoye M, Kacerovsky M, Schmid AI, Gruber S, Wolzt M, Moser E, Pacini G, Smekal G, Groop L, Roden M: Short-term exercise training does not stimulate skeletal muscle ATP synthesis in relatives of humans with type 2 diabetes. Diabetes 2009;58:1333-1341.

45 Stefan N, Thamer C, Staiger H, Machicao F, Machann J, Schick F, Venter C, Niess A, Laakso M, Fritsche A, Haring HU: Genetic variations in PPARD and PPARGC1A determine mitochondrial function and change in aerobic physical fitness and insulin sensitivity during lifestyle intervention. J Clin Endocrinol Metab 2007;92:1827-1833.

46 Finkel T, Deng CX, Mostoslavsky R: Recent progress in the biology and physiology of sirtuins. Nature 2009;460:587-591.

-47 Suwa M, Nakano H, Radak Z, Kumagai S: Endurance exercise increases the SIRT1 and peroxisome proliferator-activated receptor gamma coactivator-1alpha protein expressions in rat skeletal muscle. Metabolism 2008;57:986-998.
48 Amara CE, Shankland EG, Jubrias SA, Marcinek DJ, Kushmerick MJ, Conley KE: Mild mitochondrial uncoupling impacts cellular aging in human muscles in vivo. Proc Natl Acad Sci USA 2007;104:1057-1062.

-49 Echtay KS, Roussel D, St-Pierre J, Jekabsons MB, Cadenas S, Stuart JA, Harper JA, Roebuck SJ, Morrison A, Pickering S, Clapham JC, Brand MD: Superoxide activates mitochondrial uncoupling proteins. Nature 2002; 415:96-99.

50 Nabben M, Hoeks J, Briede JJ, Glatz JF, Moonen-Kornips E, Hesselink MK, Schrauwen P: The effect of UCP3 overexpression on mitochondrial ROS production in skeletal muscle of young versus aged mice. FEBS Lett 2008;582:4147-4152.

51 Goldstein BJ, Mahadev K, Wu X: Redox paradox: insulin action is facilitated by insulinstimulated reactive oxygen species with multiple potential signaling targets. Diabetes 2005;54:311-321.

52 Ristow M, Zarse K, Oberbach A, Kloting N, Birringer M, Kiehntopf M, Stumvoll M, Kahn CR, Bluher M: Antioxidants prevent health-promoting effects of physical exercise in humans. Proc Natl Acad Sci USA 2009; 106:8665-8670. 